\title{
QUEEN'S
UNIVERSITY
BELFAST
}

\section{Novel freeze-dried DDA and TPGS liposomes are suitable for nasal delivery of vaccine}

Yusuf, H., Ali, A. A., Orr, N., McCarthy, H. O., \& Kett, V. L. (2017). Novel freeze-dried DDA and TPGS liposomes are suitable for nasal delivery of vaccine. International Journal of Pharmaceutics.

https://doi.org/10.1016/j.jpharm.2017.09.011

\section{Published in:}

International Journal of Pharmaceutics

\section{Document Version:}

Peer reviewed version

Queen's University Belfast - Research Portal:

Link to publication record in Queen's University Belfast Research Portal

\section{Publisher rights}

() 2017 Elsevier B.V. All rights reserved. This manuscript version is made available under the CC-BY-NC-ND 4.0 license

http://creativecommons.org/licenses/by-nc-nd/4.0/,which permits distribution and reproduction for noncommercial purposes, provided the author and source are cited.

\section{General rights}

Copyright for the publications made accessible via the Queen's University Belfast Research Portal is retained by the author(s) and / or other copyright owners and it is a condition of accessing these publications that users recognise and abide by the legal requirements associated with these rights.

\section{Take down policy}

The Research Portal is Queen's institutional repository that provides access to Queen's research output. Every effort has been made to ensure that content in the Research Portal does not infringe any person's rights, or applicable UK laws. If you discover content in the Research Portal that you believe breaches copyright or violates any law, please contact openaccess@qub.ac.uk. 


\section{Accepted Manuscript}

Title: Novel freeze-dried DDA and TPGS liposomes are suitable for nasal delivery of vaccine

Authors: Helmy Yusuf, Ahlam A. Ali, Natalie Orr, Helen O. McCarthy, Vicky L. Kett

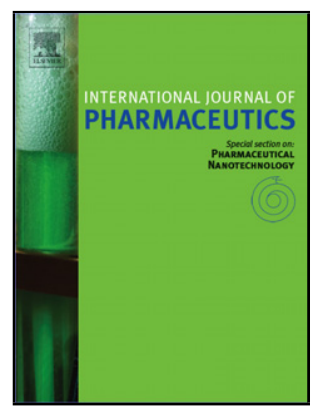

PII:

DOI:

Reference:

To appear in:

Received date:

Revised date:

Accepted date:
S0378-5173(17)30857-8

http://dx.doi.org/10.1016/j.ijpharm.2017.09.011

IJP 16991

\section{International Journal of Pharmaceutics}

Please cite this article as: Yusuf, Helmy, Ali, Ahlam A., Orr, Natalie, McCarthy, Helen O., Kett, Vicky L., Novel freeze-dried DDA and TPGS liposomes are suitable for nasal delivery of vaccine.International Journal of Pharmaceutics http://dx.doi.org/10.1016/j.ijpharm.2017.09.011

This is a PDF file of an unedited manuscript that has been accepted for publication. As a service to our customers we are providing this early version of the manuscript. The manuscript will undergo copyediting, typesetting, and review of the resulting proof before it is published in its final form. Please note that during the production process errors may be discovered which could affect the content, and all legal disclaimers that apply to the journal pertain. 
Novel freeze-dried DDA and TPGS liposomes are suitable for nasal delivery of vaccine

Helmy Yusuf ${ }^{1}$, Ahlam, A. Ali, Natalie Orr, Helen O. McCarthy, Vicky L. Kett*

School of Pharmacy, Queen's University Belfast, 97 Lisburn Road, Belfast BT9 7BL. U.K.

*Correspondence author.

Email v.kett@qub.ac.uk; telephone (0)2890 972008 ; fax +44 (0)2890 247794

\section{Graphical abstract}

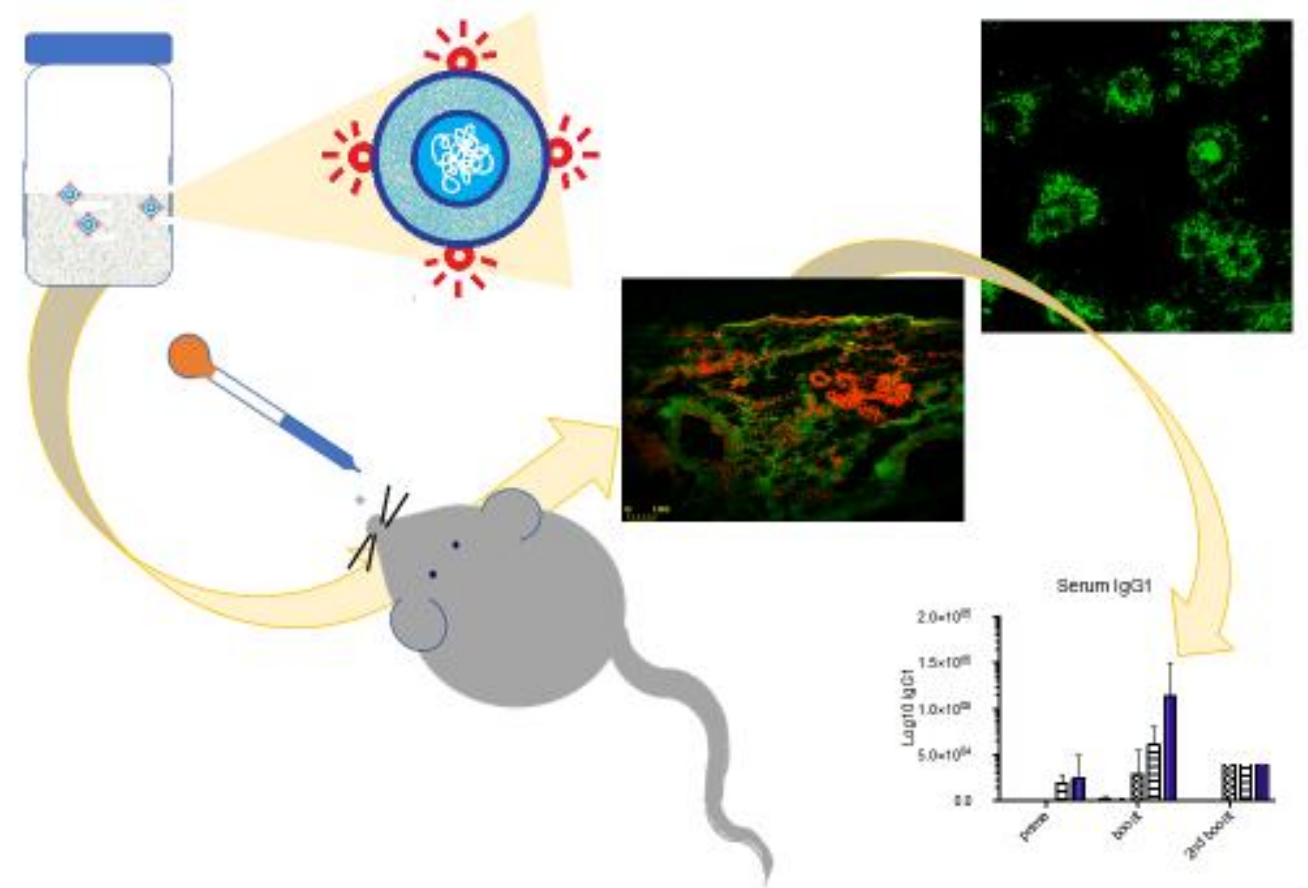

\section{Abstract}

There is a pressing need for effective needle-free vaccines that are stable enough for use in the developing world and stockpiling. The inclusion of the cationic lipid DDA and the PEG-containing

\footnotetext{
${ }^{1}$ Present address Faculty of Pharmacy, Airlangga University, Indonesia
} 
moiety TPGS into liposomes has the potential to improve mucosal delivery. The aim of this study was to develop stable lyophilized cationic liposomes based on these materials suitable for nasal antigen delivery.

Liposomes containing DDA and TPGS were developed. Size and zeta potential measurements, ex vivo, CLSM cell penetration study and cell viability investigations were made. Preliminary immunisation and stability studies using ovalbumin were performed.

The liposomes exhibited suitable size and charge for permeation across nasal mucosa. DDA and TPGS increased tissue permeation in ex vivo studies and cell uptake with good cell viability. The liposomes improved immune response both locally and vaginally when compared to i.m administration or control liposomes delivered nasally. Additionally, the lyophilized products demonstrated good stability in terms of $\mathrm{Tg}$, size and antigen retention.

This study has shown that the novel liposomes have potential for development as a mucosal vaccine delivery system. Furthermore, the stability of the lyophilized liposomes offers potential additional benefits in terms of thermal stability over liquid formats.

Keywords; liposomes; TPGS; DDA; mucosal vaccine; temperature stability; nasal

Chemical compounds studied in this article;

DDA (PubChem CID: 77293)

Ovalbumin (PubChem CID: 56832351)

Soy phosphatidyl choline (PubChem CID: 5287971)

TPGS (PubChem CID: 71406)

1 Introduction 
The majority of microbial pathogens use the mucosal surfaces as their site of entry. Vaccination is considered to be the most effective prevention against such infections. However, most vaccines are administered via injections, which are painful for the recipient, require trained personnel to administer and raise risks associated with infection at injection-site, needlestick injury and issues of disposal. Additionally, they tend to only induce weak local/mucosal immune response in contrast to the strong mucosal immunity required at the most common entry sites of pathogens. (Woodrow et al., 2012) This creates a need for mucosal adjuvants/vaccine formulations that induce strong local and humoral immune responses. (Shakya et al., 2016)

Liposomes have been hailed as good candidates for vaccine delivery systems, especially for mucosal immunization.(Heurtault et al., 2010) (Gupta et al., 2012) However, efficacy of conventional liposomes may be hampered by the barriers that could prevent the antigen reaching the mucosal immune system.(Yusuf and Kett, 2017) Cationic liposomes appear to offer benefits in terms of cell uptake but their use can generate undesirable toxicity if used at high concentrations. (Christensen et al., 2007b) The cationic lipid dimethyldioctadecylammonium (DDA) has previously been investigated for inclusion in cationic liposomes for mucosal delivery in combination with glycolipid trehalose 6,6'dibehenate.(Davidsen et al., 2005) There has been a recent upsurge in reports of pegylation to improve passage of nanoparticles through mucus (Suk et al., 2016) related to the observation that PEGylated liposomes can induce stronger mucosal immune responses than non-PEGylated liposomes as function of the surface modification.(Minato et al., 2003) Additionally, cell uptake is improved when the vitamin E-PEG 1K combination D-alpha-Tocopheryl polyethylene glycol 1000 succinate (TPGS) is used to target nanoparticles.(Muthu et al., 2011) Many liposomes are formulated with material from animal sources; plant-based materials reduce potential for contamination from livestock and are less culturally sensitive. We present for the first time a novel lyophilized liposomal formulation that combines the cationic lipid DDA with TPGS and investigate its ability to penetrate nasal tissue, improve cell uptake and induce immune response to a model antigen ovalbumin (OVA). 
Finally, as we aim to develop needle-free formulations suitable for use in the developing world we investigated the thermal stability of the freeze-dried products. of the freeze-dried products.

2 Materials and methods

2.1 Materials TPGS (high purity), DDA ( $>98 \%$ purity), OVA ( $\geq 98 \%$ in purity, lyophilized powder), Bradford's reagent, Coomasie Blue, phosphotungstic acid 5,6 carboxyfluorescein (CF), fluorescein isothiocyanate labelled bovine serum albumin (FITC-BSA), Propidium lodide (PI, $\geq 94 \%$ purity), Triton $\mathrm{X}-100$, paraformaldehyde, polyvinyl alcohol mounting medium with $\mathrm{DABCO}^{\circledR}$ and methanol (analytical grade) were purchased from Sigma-Aldrich (UK), SPC (Lipoid S75) was from Lipoid (Germany). Trehalose Dihydrate (high purity, low endotoxin) was from Ferro Pfanstiehl (USA). Chloroform (analytical grade), Tris-(hydroxymethyl)-methylamine and sodium hydroxide ( $\mathrm{NaOH})$ were from VWR (England). NuPAGE ${ }^{\circledR}$ MES SDS Running Buffer, nucleic acid sample loading buffer and Novex 4-12\% Bis-Tris Gel (1.0 mm, 10 Well) Phosphate buffered saline (PBS), Minimum Essential medium (MEM) medium containing Earle's salts and L-glutamine and Trypsin were purchased from Invitrogen (UK). SimplyBlue ${ }^{\mathrm{TM}}$ SafeStain was purchased from BioRad (UK). WST-1 reagent (2-(4iodophenyl)-3-(4-nitrophenyl)-5-(2,4-disulfophenyl)-2H-tetrazolium monosodium salt) was purchased from Roche Diagnostics Ltd (UK). Foetal calf serum (FCS) from PAA Laboratories (Austria). O.C. $T^{\mathrm{TM}}$ compound and cover slips were from Agar Scientific (UK).

\subsection{Methods}

\subsubsection{Liposome preparation}

Liposome Preparation and Characterisation. Liposomes were formulated to contain SPC alone (SPC), DDA and SPC, molar ratio 1:4 (DS), or DDA, SPC, and TPGS molar ratio 4:16:0.1 (DST). The liposomes were prepared based on the thin film hydration technique. In brief, DDA, SPC and TPGS as required were dissolved and mixed in chloroform: methanol (9:1). Solvent was evaporated using a rotary evaporator. The thin film was hydrated with trehalose and $10 \mathrm{mM} \mathrm{pH} 7.4$ tris buffer, before sonication to reduce size (Fisher Scientific, USA). To prepare CF-loaded liposomes $200 \mu \mathrm{g} / \mathrm{ml}$ 
CF was added to the hydration buffer. To prepare FITC-BSA loaded liposomes $250 \mu \mathrm{g} / \mathrm{ml}$ was added to the hydration buffer. These concentrations were chosen so that the fluorescence could be accurately recorded in order to determine localisation of the liposomes. OVA liposomes were prepared mixing OVA in Tris buffer with the liposomes to give a final concentration of $1 \mathrm{mg} / \mathrm{ml}$ OVA. The liposomes were dispensed into freeze-drying vials before lyophilization (Advantage, VirTis, USA).

\subsubsection{Liposome characterisation}

Size and zeta potential were measured before and after freeze-drying using a Malvern ZetaSizer (Malvern instruments, UK) in triplicate at $25^{\circ} \mathrm{C}$, and reported as the Z-average diameter (d. nm) $\pm \mathrm{sd}$ and $\mathrm{ZP}(\mathrm{mV}) \pm$ sd respectively. Modulated differential scanning calorimetry (Q-100, TA Instruments, New Castle, DE USA) was used to measure the Tg of the dried products in aluminium hermetic pans from $0^{\circ} \mathrm{C}$ to $200^{\circ} \mathrm{C}$; ramp $3^{\circ} \mathrm{C} / \mathrm{min}$ with modulation of $+/-1.0^{\circ} \mathrm{C}$ over 60 seconds $(n=3)$. The water content was determined by thermogravimetric analysis using a Q-500 (TA Instruments, New Castle, DE USA) ( $n=3)$. OVA encapsulation efficiency was determined by separating unencapsulated OVA from the liposomes with NANOSEP, 300K centrifuge filters (OMEGA, Pall, USA). The filtrate was diluted $5 \mathrm{x}$ with water, treated with Bradford's reagent and the absorbance measured at $595 \mathrm{~nm}$ using a Nanodrop UV-Vis spectrophotometer (Fisher scientific, USA) after 10 minutes $(n=3)$. The encapsulation efficiency of the liposomes was calculated from the ratio of unentrapped OVA and initial loading using the equation $\mathrm{EE}=[(\mathrm{Ct}-\mathrm{Cs}) / \mathrm{Ct}] \times 100 \%$, where $\mathrm{Ct}$ is the total concentration of OVA loaded and Cs is the concentration of OVA in the supernatant after liposomes were separated from the unentrapped OVA by ultracentrifugation $(n=3)$.

\subsubsection{Cell uptake studies}

L-132 Human lung epithelial cells were cultured in Nunc Cell Culture Flask (Thermo Scientific) in MEM medium containing Earle's salts and L-glutamine and supplemented with $10 \%$ foetal calf serum (FCS). The cells were incubated at $37^{\circ} \mathrm{C}$ with $5 \% \mathrm{CO}_{2}$ and $95 \%$ air to produce stock for the studies. For seeding, stock cells were treated with $1 x$ trypsin solution in PBS and incubated at $37^{\circ} \mathrm{C}$ for $2-3$ 
min. The cell suspension was further diluted with MEM medium and centrifuged at $1500 \mathrm{rpm}$ for 5 $\min$ (Eppendorf Centrifuge 5804) to obtain the cell pellet. The supernatant was removed and the pellet was re-suspended in $10 \mathrm{ml}$ MEM medium. A $200 \mu \mathrm{l}$ portion was mixed with $10 \mathrm{ml}$ counting medium (Coulter Isoton ${ }^{\circledR}$ II Diluent) and the cell population determined using a Beckman Z1 Coulter ${ }^{\circledR}$ Particle Counter. This suspension was further used for cell seeding. For cellular uptake using fluorometry, the cells were seeded at $25 \times 10^{4}$ cells/well onto 24 -well plates (VWR International) in total volume of $1 \mathrm{ml} /$ well. Twenty-four hours later, the medium was removed and replaced with the free CF solution or liposome formulation in MEM medium (10 $\mu$ l of free CF or CF-loaded liposomes in $990 \mu \mathrm{l}$ medium) and incubated for $0.5 \mathrm{~h}, 1 \mathrm{~h}$ and $2 \mathrm{~h}$ at $37^{\circ} \mathrm{C}$. Following incubation, the formulations were removed and the cells were washed twice with cold PBS and then lysed with $0.2 \%$ Triton X-100 in $0.2 \mathrm{~N} \mathrm{NaOH}$. Aliquots were transferred into black 96-well plates (Sterilin) for reading. The cell fluorescence intensity was measured using a spectrofluorometer (FLUOstar Optima, BMG Labtech, Durham, USA) at excitation and emission wavelengths of $485 \mathrm{~nm}$ and $520 \mathrm{~nm}$ respectively. Three independent experiments were performed and results are reported as mean of fluorescence intensity \pm sem. Results were validated against calibration curves constructed for each experiment. Flow Cytometry (FACS) analysis of cellular uptake was also performed using cells seeded at $50 \times 10^{4}$ cells/well into 24-well plates (VWR International) in total volume of $1 \mathrm{ml} /$ well. Following incubation with the formulations, cells were washed with cold PBS to end the cell uptake, then trypsinized with $200 \mu \mathrm{l}$ trypsin solution and incubated for 3 minutes at $37^{\circ} \mathrm{C} .1 \mathrm{ml}$ of PBS was added to each well, gently mixed before transfer to an Eppendorf tube for centrifugation to remove trypsin, extracellular liposomes and cell debris at $1500 \mathrm{rpm}$ and $4^{\circ} \mathrm{C}$ for $5 \mathrm{~min}$. Precipitated cells were re-suspended in 400 $\mu \mathrm{I}$ PBS and gently mixed to avoid cell aggregation. The cells were kept on ice for further analysis for cell-incorporated CF fluorescence using a FACSCanto II 6 colour system (BD Bioscences) flow cytometer equipped with 325, 488 and $633 \mathrm{~nm}$ lasers and analysed using BD FACS Diva ${ }^{\mathrm{TM}}$ software. The flow cytometry results are presented as histograms based on the measurement of visible and fluorescent light emission of CF in the cell population. 
Confocal Laser Scanning Microscopy (CLSM) was used to visualise the cellular uptake of the liposomes. Cells were seeded at $2 \times 10^{5}$ cells/well onto a 4-well chamber slide (Lab-Tek II; Nalge Nunc International). After 24 hours, the medium was replaced with $10 \mu$ formulation in $990 \mu$ l medium before further incubation for $1 \mathrm{~h}$ at $37^{\circ} \mathrm{C}$. The formulations were removed and the cells washed twice with cold PBS (pH 7.4). Cell were fixed using 4\% paraformaldehyde and observed using a Leica DMRE equipped with the TCS-SP2 confocal scanning system (Germany) with an excitation wavelength $488 \mathrm{~nm}$.

\subsubsection{Cell viability}

Cell viability was determined following liposome incubation using a colorimetric assay. (Chang, - Tai et al. 2011, Hama, Utsumi et al. 2012) L-132 cells were seeded at $25 \times 10^{3}$ cells/well in $200 \mu \mathrm{l} /$ well in 96-well plates (VWR International) and cultivated for 24 hours. The medium was removed and replaced with $20 \mu \mathrm{l}$ of liposomes and $180 \mu \mathrm{l}$ medium to give final DDAB concentrations in the range $0.25-2.5 \mathrm{mg} / \mathrm{ml}$, then incubated for $1 \mathrm{~h}, 3 \mathrm{~h}$ and $5 \mathrm{~h}$ at $37^{\circ} \mathrm{C}$. The control was medium alone. Following incubation, the liposomes were removed and replaced with $100 \mu$ l medium. $10 \mu \mathrm{L}$ of WST-1 reagent were added to each well and incubated for an additional 2 hours at $37^{\circ} \mathrm{C}$. Cell viability was determined from the optical density at $450 \mathrm{~nm}$ using a EL808 Microplate Reader (Bio-Tek Instruments, USA) and expressed as percentage of cell viability of liposome-exposed cells compared to the control group, where the control is defined as $100 \%$ viable. Results are the mean values of three independent experiments.

2.2.5 Ex vivo study. The tissue permeation study was carried out using a Franz permeation cell and Bovine nasal mucosa obtained from a local slaughter house within two hours of slaughter and prepared as described previously. (Chen et al., 2013) The recipient compartment contained Krebs Bicarbonate Ringer's (KBR) buffer $\mathrm{pH} 7.4$ stirred constantly at $37^{\circ} \mathrm{C}$ with jacketed water flow. Tissue sections of $1.5 \mathrm{~cm}^{2}$ were placed between the recipient and donor compartments and $0.5 \mathrm{ml}$ of free CF, FITC-BSA solutions or reconstituted liposomes were loaded into the donor compartment and 
incubated for 1 hour. The negative control was KBR alone. The tissues were washed with KBR buffer and embedded in $\mathrm{OCT}^{\mathrm{TM}}$ compound, snap frozen in liquid nitrogen and preserved at $-80^{\circ} \mathrm{C}$ before cryosection into $10 \mu \mathrm{m}$ thickness using a Microtome Cryostat (Leica CM 1900) at $-20^{\circ} \mathrm{C}$ and gently attached to a glass slide for analysis under Nikon ECLIPSE TE-300 fluorescence microscope, images were captured with a Nikon DXM 1200 Digital Camera (Tokyo, Japan). The tissue was stained with PI to visualise the cell nuclei then washed and immediately mounted using polyvinyl alcohol mounting medium with $\mathrm{DABCO}^{\circledast}$ and covered. The nasal sections were further studied by CLSM using an Olympus BX-60 (Tokyo, Japan) attached to BioRad $\mu$-Radiance laser scanning confocal system (Hemel Hempstead, UK). Green fluorescence was visualized at an excitation wavelength $485 \mathrm{~nm}$ and emission wavelength $515 \mathrm{~nm}$; red fluorescence was visualised using an excitation wavelength 530 $\mathrm{nm}$ and emission wavelength $625 \mathrm{~nm}$.

2.2.6 Immunisation study. This was conducted according to the guidelines provided by UK Animals (Scientific Procedures) Act 1986 and was approved by the Department of Health, Social Services and Public Safety, Northern Ireland, UK. Female C57/BL6 mice (6-8 weeks) were purchased from Charles River Laboratories. The animals were housed in an open facility at $21^{\circ} \mathrm{C}$ and $50 \%$ humidity with food and water ad libitum. Five groups of 5 mice were immunized three times (day $0,14,28$ ) as described in Table 1. Intranasal immunization was carried out by instilling $5 \mu$ l of formulation in each nostril, while mice were anesthetized by intraperitoneal (i.p.) injection of Rompum and Ketasat mix. Intramuscular immunization was carried out by injecting 25 ul PBS containing $10 \mu \mathrm{g}$ OVA. Samples were collected on day 14, 28 and 42 . Blood was collected from the tail vein and the sera were separated by centrifugation for $15 \mathrm{~min}$ at $4^{\circ} \mathrm{C}, 10,000 \mathrm{rpm}$ (Sigma 3K30, Germany). Vaginal wash samples were collected by carefully instilling and withdrawing $100 \mu \mathrm{L} 0.1 \%$ BSA in PBS into the vagina of anaesthetised mice. Immediately after euthanizing the mice by $\mathrm{CO} 2$ asphyxiation (on day 42) nasal washes were collected by carefully instilling and withdrawing $100 \mu l 0.1 \%$ BSA in PBS into the nostrils. Additional blood samples were collected by cardiac puncture. OVA-specific IgA, IgG1 and IgG2a antibodies were measured by ELISA method. In brief, ready ELISA Kit contains 96-well 
OVA-specific IgA (Genemed Synthesis Inc. San Antonio, USA) or OVA-specific IgG1/IgG2a (Alpha Diagnostic international, San Antonio, USA) were used to determine the antibody responses. Diluted sera and mucosal washes were incubated for 60 minutes $(100 \mu \mathrm{l} /$ well). After washing, the plates were incubated with specific anti-mouse IgA/IgG1/IgG2a horseradish peroxidase-conjugate (HRP) for 30 minutes, washed again then chromogenic substrate (TMB) was added to the wells (100 $\mu \mathrm{l} /$ well). After 15 minutes the reaction was stopped with $1 \% \mathrm{H}_{2} \mathrm{SO}_{4}$. Absorbance at $450 \mathrm{~nm}$ was then measured using an ELISA microwell reader. Antibody concentrations were calculated relative to mouse anti-ovalbumin reference calibrators. Sera were analysed for $\operatorname{IgG} 1$ and $\lg G 2 a$, while the mucosal washes were analysed for IgA.

(Table 1 near here)

2.2.7 Stability Study: Freeze-dried liposomes were stored at $4^{\circ} \mathrm{C}\left(2-8^{\circ} \mathrm{C}\right)$ or $20^{\circ} \mathrm{C} /$ ambient humidity in sealed glass vials. Samples were analysed at 4,8 and 12 weeks $(n=4)$ for $\operatorname{Tg}$, water content, encapsulation efficiency, liposome size and charge.

2.2.8 Statistical Analysis The tests were carried out using the IBM SPSS Statistics Software (IBM Corporation, New York, USA) and Graphpad ${ }^{\circledR}$ InStat software (San Diego, CA). Non-parametric Kruskal - Wallis or Mann - Whitney $\mathrm{U}$ test were used to analyse the results of physicochemical characterization, while a parametric one way ANOVA test was used to analyse the in vitro experimental data. Confidence limits of $95 \%$ were used to determine statistical significance.

3 Results

3.1 Size and Charge.

Size and charge of empty and CF-loaded liposomes are given in Table 2. OVA-loaded liposomes exhibited size and charge of $265.9( \pm 51.9) \mathrm{nm}$ and $56.5( \pm 11.9) \mathrm{mV}$ respectively.

(Table 2 near here)

3.2 Cell uptake 
Quantitative analysis of CF in the epithelial cells after incubation with CF formulations is shown in Figure 1a. The results showed that the amount of CF incorporated into the epithelial cells increased in the order of Free CF $<$ SPC < DS < DST liposomes. These differences were apparent within 30 min and seemed to be time-dependent, exhibiting statistically significantly differences at each time point (one way-ANOVA, $\mathrm{p}<0.05$ ). Flow cytometric analysis was also performed to discriminate the cellincorporated CF fluorescence based on the intensity of CF and showed distinct populations of fluorescent cells. CLSM visualisation of the cellular uptake of CF-encapsulating liposomes after 1 hour (Figure 1b-d) show that CF fluorescence observed in the epithelial cells increased in the order of free CF $<$ CF-loaded SPC lip $<$ CF-loaded DST.

(Figure 1 near here)

\subsection{Cell Viability Study}

The results of the cell viability study after incubation of up to 5 hours with the empty DST liposomes showed no significant differences when compared with the control group, indicating that the formulation exerted no ill effect on these cells under the study conditions (Figure 2). Additionally repeat of this experiments at concentrations up to ten times higher, showed no deleterious effect on the viability of the cells (Supplementary Figure A).

(Figure 2 near here)

3.4 Permeability and Penetration Into Bovine Nasal Tissue: ex vivo Study

The permeation and distribution of free CF solution andCF-loaded liposomes are shown in the CLSM images depicted in Figure 3. DST liposomes demonstrably enhanced penetration of CF across the nasal mucosa compared to both free solution and SPC liposomes. Free CF was only able to penetrate interstitial areas, free CF was only observed by fluorescence microscopy prior to the PI staining and washing steps (data not shown). A similar pattern of distribution was observed for FITCBSA (Supplementary material Figure B). 
(Figure 3 near here)

\subsection{Immunization Study}

Since the DS liposomes showed poor cellular uptake and to minimise the number of animals used in this preliminary animal study, only the DST liposomes were taken forward to be investigated as mucosal vaccine delivery systems. Substantial differences were observed between the serum IgG1 responses elicited in the DST liposome group and the other groups (Figure 4a). The serum IgG1 results obtained for intranasal OVA-DST liposomes immunized mice were significantly different from the rest of the groups with notable trends over the experimental period. At day 14 following the primary immunization with liposomes, only the i.n. OVA-loaded DST and i.m. free OVA routes showed induced immune responses, with comparable OVA-specific IgG1 titers ( $p>0.05)$. Both boosts increased the IgG1 responses in these two groups Overall, the results showed that the amount of serum IgG1 increased in the order of i.n. free OVA $<$ i.m. free OVA $<$ i.n. OVA-loaded DST; while the groups that received PBS and empty DST showed negligible responses. In contrast, the serum IgG2a responses were extremely weak in all groups (Figure 4b). Since a semi-quantitative analysis was used to obtain the IgG2a data; no significant differences were noted between the groups (one way ANOVA, $p>0.05)$. We further investigated OVA-specific IgA responses at mucosal sites. The results showed that intranasal immunization with the OVA-DST liposomes, elicited higher slgA response at the mucosal site for both nasal and vaginal samples (Figure $4 c \& d$ ). slgA levels in vaginal washes were significantly higher for i.n. OVA-DST liposomes and showed increases with each boost; while in contrast, the i.m. free OVA showed a decrease as the mice received more vaccinations. As expected, the mice groups that received PBS (naïve control group) and empty liposomes showed no responses. (Figure 4 near here)

3.6 Stability. The liposomes exhibited excellent stability over 12 -weeks at both $4^{\circ} \mathrm{C}$ and $20^{\circ} \mathrm{C}$ as indicated by results in Figure 5. The high OVA encapsulation efficiency was maintained, as were the size and charge, while there was no evidence of protein degradation shown by SDS-PAGE analysis 
(supplementary material figure C). Although refrigerated samples exhibited slightly higher Tgs throughout the study, this was not significant and there was no significant change in either Tg or water content (supplementary material figure D) throughout the trial (Kruskall Wallis, $p>0.05$ ).

(Figure 5 near here)

\section{Discussion}

4.1 Size and charge. It is known that small particles with cationic charge (Billiet et al., 2012) show better internalization; modifying liposomes with TPGS had no significant effect on either property, producing DST liposomes with size and charge characteristics that are desirable for cell uptake.

4.2 Cell uptake. The cellular CF intensity of DST liposomes measured by fluoremetry was the highest at all time points. The FACS analysis backed up these findings; cells incubated with CF-loaded DST liposomes exhibited the highest CF intensity with a very clear difference from the rest of the populations, and again with significant uptake clearly seen within half an hour. The amount of CF incorporated into the epithelial cells increased in the order of free CF $<$ SPC liposomes $<$ DST liposomes. While the difference between the DST and SPC liposomes could be attributed to the known uptake enhancement of positively charged nanoparticles, (Korsholm et al., 2012) the DS liposomes exhibit similar charge positive charge, yet were not as effective. The additional uptake is therefore attributed to the presence of TPGS, which had little effect on the liposome charge (Table 2) and has been reported to increase cellular uptake of liposomes through endocytosis based on observed cellular uptake within 30 minutes. (Muthu et al., 2011) Our CF uptake results mirror those, indicating the active endocytosis as a plausible mechanism of cellular uptake. Alternatively cationic liposomes are thought to be internalised through membrane fusion (Babiuk et al., 2000). The CLSM images confirmed the results of the fluoremetry and FACS experiments; the inclusion of PEG (TPGS) seemed to enhance liposome internalization (Figure 1e-g.). Taken together the cell uptake data demonstrate the clear benefit of DDA and TPGS in the formulation. 
4.3 We suggest that the enhanced permeability of the DST liposomes shown in both the cell culture and ex vivo imaging could be caused by the electrostatic attraction between the cationic DST liposomes and the negatively charged nasal mucosa (Samson et al., 2012). This strong interaction may further enhance the nasal mucosa contact time, leading to higher local concentration at the site of administration and the improved penetration demonstrated by the DST liposomes. Although it has been reported that the mucoadhesive mechanism of PEGylated particles is through hydrogen bonding, polymer entanglements with mucins, or a combination of these mechanisms (Bures, Huang et al. 2001, Lai, Wang et al. 2009), studies have shown that pegylated particles coated in 5K PEG seems to improve penetration through mucus perhaps by rendering nanoparticles more "slippery" (Wang et al., 2008), we suggest that TPGS acts in this maner to aid diffusion through the mucus layer.

Cell viability

4.4 The primary concern in this cell viability study was related to the use of cationic lipids that have been widely known to be highly cytotoxic, especially in the area of nucleic acid delivery (Kiefer et al., 2004). Therefore, using an acceptable and safe dose in the formulation is one of critical factors that may overcome this problem. Our developed formulation used the cationic lipid DDA at a concentration that has previously been shown to be safe.(Christensen et al., 2007a) The data showed no ill effects of the DST liposomes over the concentrations and time period evaluated, although further in vivo studies wolud be required to evaluate in vivo safety.

4.5 In this preliminary immunisation study, we focused on the determination of IgG subclasses to find out the type of the immune response elicited by the developed liposomes formulation. The results showed that encapsulation of OVA into DST liposomes induced high level of IgG1 but not IgG2a antibody after intranasal administration. The high titer of serum IgG1 and lower IgG2a response indicated that the immune response was predominantly Th2- type. Furthermore, it is important to note that our results were better than a similar nasal vaccination study, despite those 
formulations including double the dose of OVA. (Slütter et al., 2010) In contrast to IgG1 subclasses, the kinetics and magnitude of the IgG2a response are both strongly affected by the administration route. (Mohanan et al., 2010) It has been reported that sensitization of mice using OVA as antigen model normally results in Th2-type cell humoral immunity. (Harada et al., 2012) Based on these prior findings it is difficult to conclude from our data whether the type of immune response induced was solely influenced by the antigen aspect and to a less extent by the delivery system; or the type of immune response would be different if other model antigen used in the developed formulation. Therefore, further testing of the developed formulation with different model antigen and administration route would be of particular interest for future studies. Additionally the Th2-type response is important in allergic immune response and extrinsic asthma (Wills-Karp, 1999). Hence, vaccine formulations that have an ability to elicit Th2-type immune response might be potentially useful for these diseases. The slgA levels in the nasal washes offer supporting evidence that liposomes promote the production of slgA in the nasal mucosa, respiratory tract, and trachea. (Alving, 1992) Additionally, the induced nasal slgA levels agreed with the serum IgG1 titers, leading us to suggest that intranasal immunization using DST liposomes could induce an enhanced sIgA antibody response and provide better protection in the respiratory tract against pathogenic invasion.Furthermore, the IgA nasal and vaginal titres indicated that the common mucosal immune system was activated throughout the body. (Farris and Morrison, 2011) Future works i.e. collecting samples from pulmonary lavages may give additional information to corroborate this hypothesis.

4.6 The high and sustained $\mathrm{Tg}$ was attributed to the trehalose commonly used to protect freezedried therapeutics (Craig et al., 1999) (McGarvey et al., 2003), which was also able to maintain size and charge of the liposomes in the desirable range.

\section{Conclusions}

The preliminary in vivo study gave evidence of the potential for the system for nasal delivery of a model antigen. Future work could investigate a "real" antigen and would include further profiling of 
the immune response generated. Finally a more wide-ranging stability study would conform to ICH accelerated testing conditions. In summary, the promising features exhibited by the results of the in vitro, ex vivo, in vivo and stability studies offer strong evidence of the potential of the developed DST liposomes for mucosal delivery of vaccine in a stable format. The L-132 cell line used in this study is similar to nasal epithelial cells in terms of their morphology and ciliary activity (Comer et al., 2012). The 'united airway' disease model (Rimmer and Ruhno, 2006) strongly correlated inflammatory cytokine levels at basal levels and after stimulation

Acknowledgement HY's work was financially supported by the Indonesian Government.

\section{Reference}

Alving, C.R., 1992. Immunological Aspects Of Liposomes - Presentation And Processing Of Liposomal Protein And Phospholipid Antigens. Biochim. Biophys. Acta 1113, 307-322.

Babiuk, S., Baca-Estrada, M., Babiuk, L.A., Ewen, C., Foldvari, M., 2000. Cutaneous vaccination: the skin as an immunologically active tissue and the challenge of antigen delivery. J. Controlled Release 66, 199-214.

Billiet, L., Gomez, J.P., Berchel, M., Jaffres, P.A., Le Gall, T., Montier, T., Bertrand, E., Cheradame, H., Guegan, P., Mevel, M., Pitard, B., Benvegnu, T., Lehn, P., Pichon, C., Midoux, P., 2012. Gene transfer by chemical vectors, and endocytosis routes of polyplexes, lipoplexes and lipopolyplexes in a myoblast cell line. Biomaterials 33, 2980-2990.

Chen, K.H., Di Sabatino, M., Albertini, B., Passerini, N., Kett, V.L., 2013. The effect of polymer coatings on physicochemical properties of spray-dried liposomes for nasal delivery of BSA. Eur. J. Pharm. Sci. 50, 312-322.

Christensen, D., Foged, C., Rosenkrands, I., Nielsen, H.M., Andersen, P., Agger, E.M., 2007a. Trehalose preserves DDA/TDB liposomes and their adjuvant effect during freeze-drying. Biochim. Biophys. ActaBiomembr. 1768, 2120-2129.

Christensen, D., Korsholm, K.S., Rosenkrands, I., Lindenstrom, T., Andersen, P., Agger, E.M., 2007b. Cationic liposornes as vaccine adjuvants. Expert Review of Vaccines 6, 785-796.

Comer, D.M., Elborn, J.S., Ennis, M., 2012. Comparison of Nasal and Bronchial Epithelial Cells Obtained from Patients with COPD. Plos One 7, 8.

Craig, D.Q.M., Royall, P.G., Kett, V.L., Hopton, M.L., 1999. The relevance of the amorphous state to pharmaceutical dosage forms: glassy drugs and freeze dried systems. Int. J. Pharm. 179, 179-207.

Davidsen, J., Rosenkrands, I., Christensen, D., Vangala, A., Kirby, D., Perrie, Y., Agger, E.M., Andersen, P., 2005. Characterization of cationic liposomes based on dimethyldioctadecylammonium and synthetic cord factor from $M$. tuberculosis (trehalose 6,6 '-dibehenate) - A novel adjuvant inducing both strong $\mathrm{CMI}$ and antibody responses. Biochim. Biophys. Acta-Biomembr. 1718, 22-31.

Farris, C.M., Morrison, R.P., 2011. Vaccination against Chlamydia Genital Infection Utilizing the Murine C-muridarum Model. Infect. Immun. 79, 986-996.

Gupta, P.N., Pattani, A., Curran, R.M., Kett, V.L., Andrews, G.P., Morrow, R.J., Woolfson, A.D., Malcolm, R.K., 2012. Development of liposome gel based formulations for intravaginal delivery of the recombinant HIV-1 envelope protein CN54gp140. Eur. J. Pharm. Sci. 46, 315-322. 
Harada, Y., Tanaka, S., Motomura, Y., Harada, Y., Ohno, S., Ohno, S., Yanagi, Y., Inoue, H., Kubo, M., 2012. The 3 ' Enhancer CNS2 Is a Critical Regulator of Interleukin-4-Mediated Humoral Immunity in Follicular Helper T Cells. Immunity 36, 188-200.

Heurtault, B., Frisch, B., Pons, F., 2010. Liposomes as delivery systems for nasal vaccination: strategies and outcomes. Expert Opinion on Drug Delivery 7, 829-844.

Kiefer, K., Clement, J., Garidel, P., Peschka-Suss, R., 2004. Transfection efficiency and cytotoxicity of nonviral gene transfer reagents in human smooth muscle and endothelial cells. Pharm. Res. 21, 10091017.

Korsholm, K.S., Andersen, P.L., Christensen, D., 2012. Cationic liposomal vaccine adjuvants in animal challenge models: overview and current clinical status. Expert Review of Vaccines 11, 561-577.

McGarvey, O.S., Kett, V.L., Craig, D.Q.M., 2003. An investigation into the crystallization of alpha,alphatrehalose from the amorphous state. J. Phys. Chem. B 107, 6614-6620.

Minato, S., Iwanaga, K., Kakemi, M., Yamashita, S., Oku, N., 2003. Application of polyethyleneglycol (PEG)-modified liposomes for oral vaccine: effect of lipid dose on systemic and mucosal immunity. J. Controlled Release 89, 189-197.

Mohanan, D., Slutter, B., Henriksen-Lacey, M., Jiskoot, W., Bouwstra, J.A., Perrie, Y., Kundig, T.M., Gander, B., Johansen, P., 2010. Administration routes affect the quality of immune responses: A crosssectional evaluation of particulate antigen-delivery systems. J. Controlled Release 147, 342-349.

Muthu, M.S., Kulkarni, S.A., Xiong, J., Feng, S.-S., 2011. Vitamin E TPGS coated liposomes enhanced cellular uptake and cytotoxicity of docetaxel in brain cancer cells. Int. J. Pharm. 421, 332-340.

Rimmer, J., Ruhno, J.W., 2006. Rhinitis and asthma: united airway disease. Med. J. Aust. 185, 565-571. Samson, G., de la Calera, A.G., Dupuis-Girod, S., Faure, F., Decullier, E., Paintaud, G., Vignault, C., Scoazec, J.Y., Pivot, C., Plauchu, H., Pirot, F., 2012. Ex vivo study of bevacizumab transport through porcine nasal mucosa. Eur. J. Pharm. Biopharm. 80, 465-469.

Shakya, A.K., Chowdhury, M.Y.E., Tao, W.Q., Gill, H.S., 2016. Mucosal vaccine delivery: Current state and a pediatric perspective. J. Controlled Release 240, 394-413.

Slütter, B., Bal, S., Keijzer, C., Mallants, R., Hagenaars, N., Que, I., Kaijzel, E., van Eden, W., Augustijns, P., Löwik, C., Bouwstra, J., Broere, F., Jiskoot, W., 2010. Nasal vaccination with N-trimethyl chitosan and PLGA based nanoparticles: Nanoparticle characteristics determine quality and strength of the antibody response in mice against the encapsulated antigen. Vaccine 28, 6282-6291.

Suk, J.S., Xu, Q.G., Kim, N., Hanes, J., Ensign, L.M., 2016. PEGylation as a strategy for improving nanoparticle-based drug and gene delivery. Adv. Drug Del. Rev. 99, 28-51.

Wang, Y.Y., Lai, S.K., Suk, J.S., Pace, A., Cone, R., Hanes, J., 2008. Addressing the PEG Mucoadhesivity Paradox to Engineer Nanoparticles that "Slip" through the Human Mucus Barrier. Angew. Chem.-Int. Edit. 47, 9726-9729.

Wills-Karp, M., 1999. Immunologic basis of antigen-induced airway hyperresponsiveness. Annu. Rev. Immunol. 17, 255-281.

Woodrow, K.A., Bennett, K.M., Lo, D.D., 2012. Mucosal Vaccine Design and Delivery, in: Yarmush, M.L. (Ed.), Annual Review of Biomedical Engineering, Vol 14. Annual Reviews, Palo Alto, pp. 17-46.

Yusuf, H., Kett, V., 2017. Current prospects and future challenges for nasal vaccine delivery. Human vaccines \& immunotherapeutics 13, 34-45.

\section{Figure List}

Figure 1 a) Incubation of human lung epithelial cells with CF-loaded liposomes at $37^{\circ} \mathrm{C}$ showed the effect of liposome entrapment on cellular uptake of CF. Results are mean value $\pm \operatorname{sem}(n=3) .{ }^{*} p<0.05$,

${ }^{* *} p<0.01$ compared with the SPC liposomes. Flow cytometric analysis of cell-incorporated CF 
fluorescence in three different incubation times; (b) $0.5 \mathrm{~h}$, (c) $1 \mathrm{~h}$, (d) $2 \mathrm{~h}$. Grey area (negative cells). thin solid line (empty liposomes), dashed line (free CF), grey line (CF-loaded SPC liposomes), black solid line (CF-loaded DST liposomes). CLSM images of lung epithelial cells incubated for $1 \mathrm{~h}$ with (e) Free CF, (f) CF-Loaded SPC liposomes, and (g) CF-Loaded DST liposomes.

Figure 2. Cell viability obtained by WST-1 assay that measures the metabolic activity of viable cells with respect to the control after 1, 3 and 5 hours incubation with DST liposomes ( $n=3 \pm \operatorname{sem}$ ).

Figure 3 CLSM images of cryosectioned bovine nasal tissues after 1 hour penetration of formulations and nucleus staining with PI; a) control; b) free CF; c) CF-loaded SPC liposomes; d) CF-loaded DST liposomes

Figure 4 a) OVA-specific serum IgG1 titers after vaccinations. Data are presented as mean \pm sem of $\mathrm{n}=4$ to $\left.5 .{ }^{*} \mathrm{p}<0.05 ; \mathrm{b}\right)$ OVA-specific serum IgG2a titers after vaccinations. Data are presented as mean \pm sem of $n=4$ to 5 ; c) OVA-specific lgA titers from vaginal wash after vaccinations. Data are presented as mean \pm sem of $n=4$ to $5 .{ }^{*} p<0.05$; d) OVA-specific IgA titers from nasal wash at day 42 . Data are presented as mean \pm sem of $n=4$ to $5 .{ }^{* *} p<0.01$.

Figure 5 a) Size; b) zeta potential; c) Tg and d) encapsulation efficiency of DST liposomes over 12-week storage at $4^{\circ} \mathrm{C}$ and $20^{\circ} \mathrm{C}$. Data are presented as mean $\pm \operatorname{sem}(n=4) .{ }^{*} p<0.05,{ }^{* *} p<0.01$. 
a)

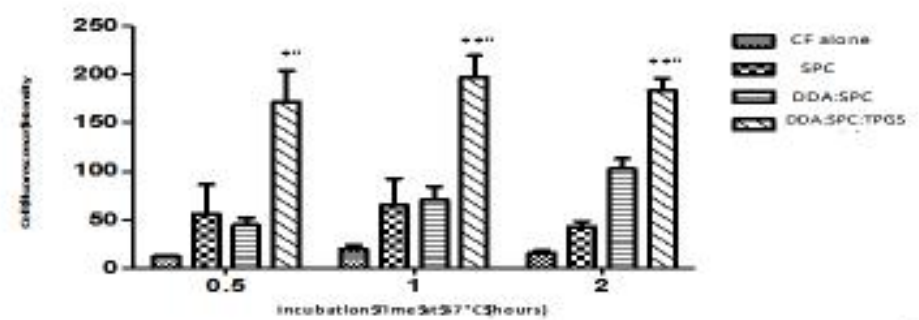

b)

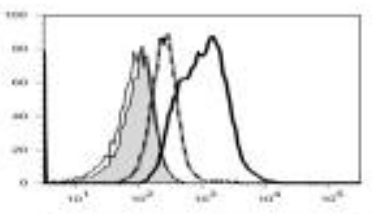

e)

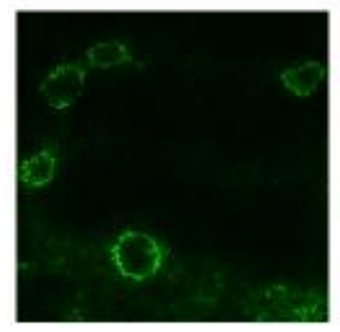

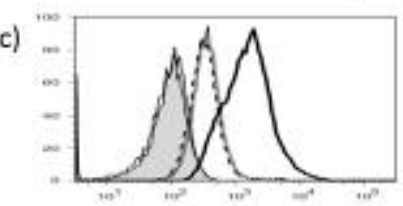

d)
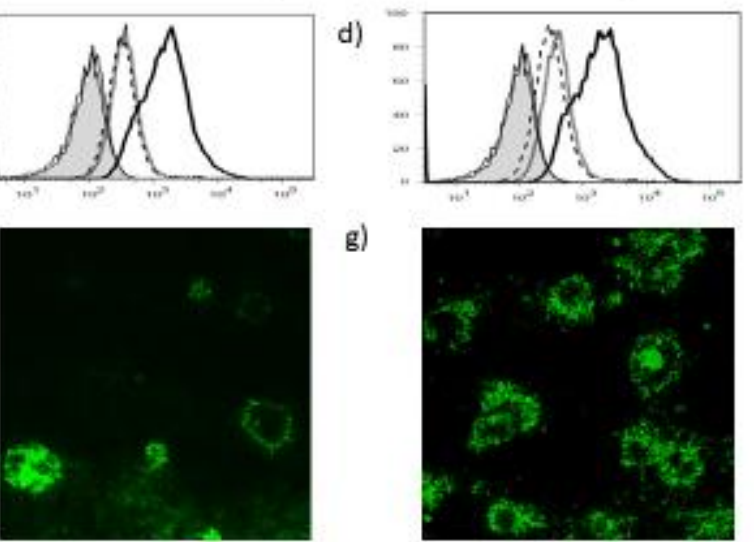

g)
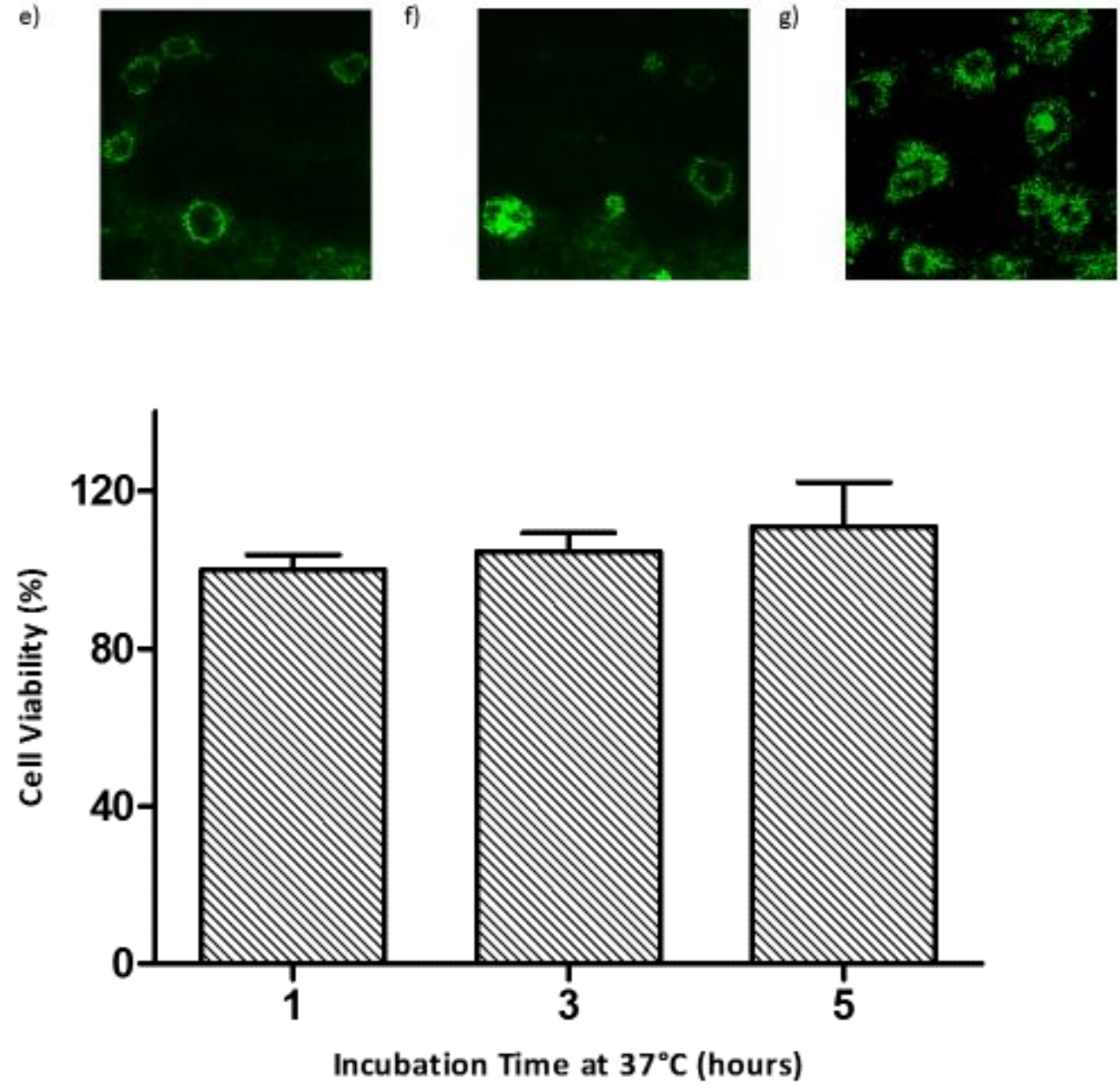
a)

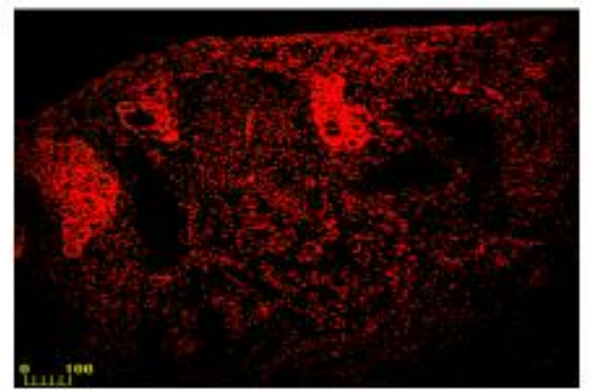

c)

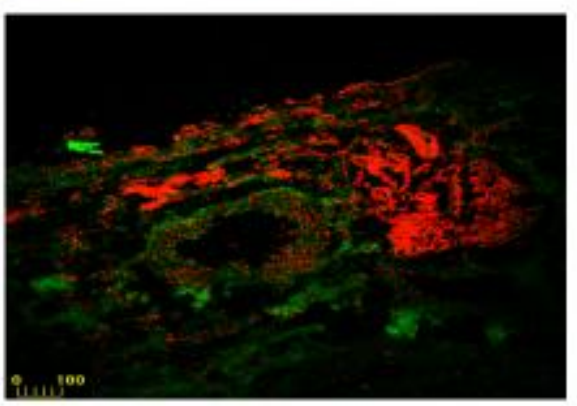

b)

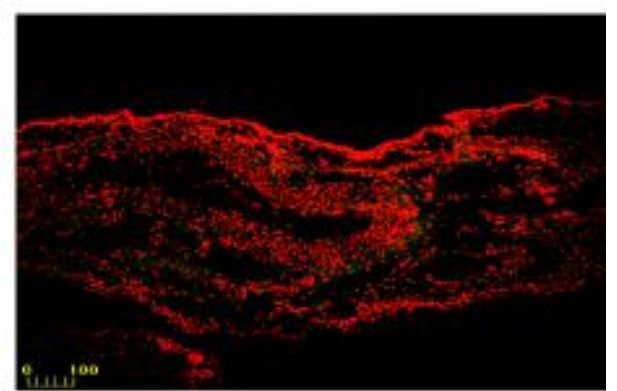

d)

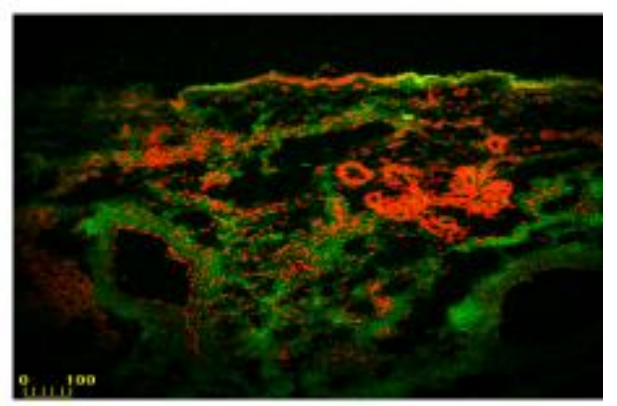

b)

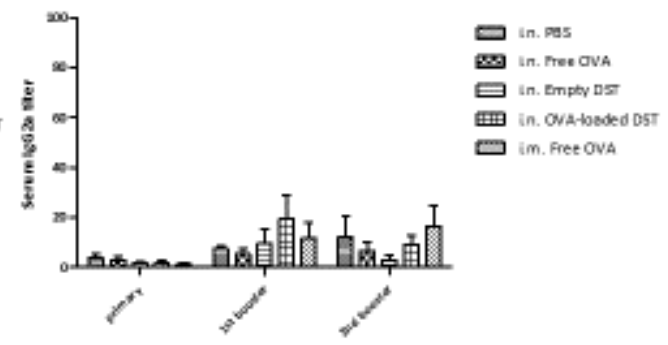

d)

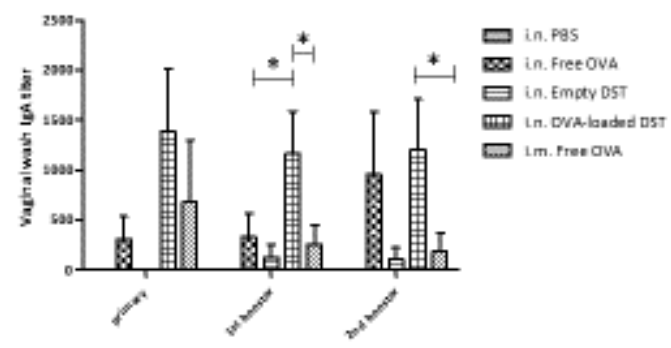


a)

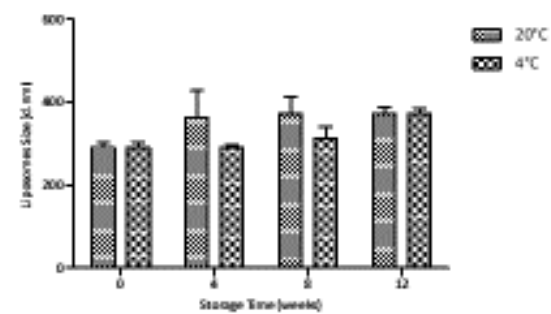

c)

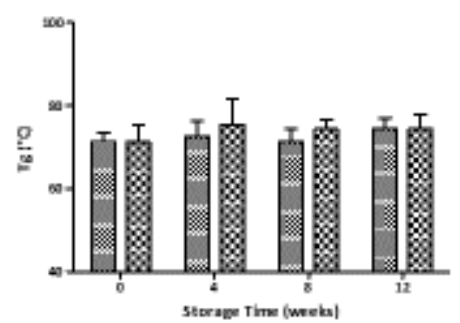

b)

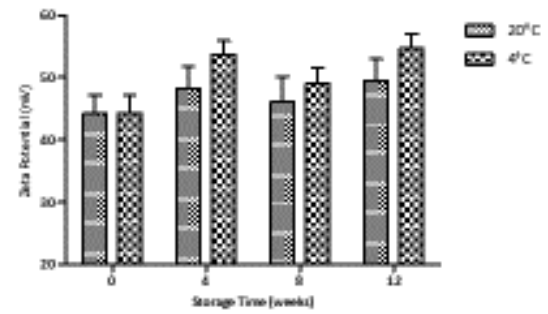

d)

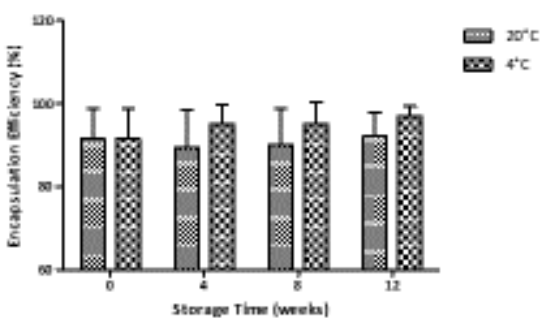

List of Tables

Table 1. Antigen formulations and administration routes.

\begin{tabular}{|c|c|c|c|c|}
\hline Group & Formulations & OVA & Route of & Number of \\
\hline & & Dose & Administration & Mice \\
\hline 1 & PBS as Naïve Control (10 $\mu \mathrm{l})$ & $10 \mu \mathrm{g}$ & intranasal & 5 \\
\hline 2 & Free -OVA in PBS $(10 \mu \mathrm{l})$ & $10 \mu g$ & intranasal & 5 \\
\hline 3 & Empty DST Liposomes (10 $\mu \mathrm{l})$ & $10 \mu g$ & intranasal & 5 \\
\hline 4 & OVA -loaded DST Liposomes (10 $\mu \mathrm{l})$ & $10 \mu g$ & intranasal & 5 \\
\hline 5 & Free -OVA in PBS $(25 \mu \mathrm{l})$ & $10 \mu g$ & intramuscular & 5 \\
\hline
\end{tabular}

Table 2. Size and ZP of empty and CF -loaded liposomes. Data presented as mean values $\pm s d,(n=6)$ 


\begin{tabular}{lcccccc}
\hline & SPC lip & DS lip & DST lip & SPC lip & DS lip & DST lip \\
\hline Empty & $91.8 \pm 2.2$ & $102.7 \pm 1.1$ & $104.0 \pm 4.4$ & $-30.1 \pm 3.0$ & $57.2 \pm 3.0$ & $53.2 \pm 2.1$ \\
\hline CF- & & & & & \\
Loaded & $93.6 \pm 0.9$ & $95.9 \pm 0.7$ & $109.4 \pm 2.1$ & $-29.9 \pm 2.2$ & $51.9 \pm 3.6$ & $50.4 \pm 2.1$
\end{tabular}

